Article

\title{
'Hot, Young, Buff': An Indigenous Australian Gay Male View of Sex Work
}

\author{
Corrinne Sullivan \\ School of Social Sciences, Western Sydney University, Penrith, NSW 2751, Australia; \\ E-Mail: corrinne.sullivan@westernsydney.edu.au
}

Submitted: 13 July 2020 | Accepted: 2 September 2020 | Published: 15 April 2021

\begin{abstract}
Research has historically constructed youths who are involved in sex work as victims of trafficking, exploitation, poverty, and substance abuse. These perceptions often cast the sex worker as deviant and in need of 'care' and 'protection.' Rarely seen are accounts that provide different perspectives and positioning of youth engaged in sex work. This article explores the lived experiences of Jack, a young gay cis-male who identifies as Indigenous Australian. Despite being a highly successful sex worker, his involvement in such a stigmatised occupation means that he must navigate the social and cultural perceptions of 'deviant' and 'dirty' work. This qualitative study explores the ways in which Jack negotiates his work, his communities, and the capitalisation of his sexuality. Drawing on Indigenous Standpoint Theory and wellbeing theory, Jack's choice of sex work is explored through the intersections of sexuality and culture, with the consequences of Jack's social and emotional wellbeing emerging as his narrative unfolds.
\end{abstract}

\section{Keywords}

gay; Indigenous; LGBTI+; male; male sex work; queer; sex work; wellbeing

\section{Issue}

This article is part of the issue "Young, Indigenous, LGBTIQ+: Understanding and Promoting Social and Emotional Wellbeing" edited by Karen Soldatic (Western Sydney University, Australia), Linda Briskman (Western Sydney University, Australia), William Trewlynn (BlaQ Aboriginal Corporation, Australia), John Leha (BlaQ Aboriginal Corporation, Australia), Corrinne Sullivan (Western Sydney University, Australia) and Kim Spurway (Western Sydney University, Australia).

(C) 2021 by the author; licensee Cogitatio (Lisbon, Portugal). This article is licensed under a Creative Commons Attribution 4.0 International License (CC BY).

\section{Introduction}

Sex work can take many forms but, generally speaking, it is an exchange of sexual-based services in exchange for money, or other in-kind goods or services of value, such as accommodation, drugs and/or alcohol, transportation, and gifts (Hubbard, 2019). There is a large body of literature crossing numerous academic disciplines addressing sex work as a multifaceted industry grounded in economic (Hubbard, 2019; van der Meulen, Durisin, \& Love, 2013), social (Smith, Grov, Seal, \& McCall, 2013), cultural (Sanders, 2013; Sullivan, 2018a), political (Weitzer, 2009), and sexual and gender expression (Gamson \& Moon, 2004; Sullivan \& Day, 2019a). Predominantly, sex work literature focusses on cis-female sex workers and almost exclusively on Western subject positioning, only rarely are people of colour, including Indigenous Australians, the focus of, or even included in, sex work studies (Sullivan, 2018a). Another significant absence in the research is age-based: Youths involved in sex work are rarely mentioned, though when it occurs they are usually framed as victims of trafficking (Ditmore, 2011; Mehlman-Orozco, 2015), exploitation (Ditmore, 2011), homelessness (Frederick, 2014), are routinely intermixed with poverty and substance abuse (Frederick, 2014; Lantz, 2005; Mendes, Snow, \& Baidawi, 2014) and in need of 'care' and 'protection' (Ditmore, 2011). It is prudent to emphasise that given the evidence presented in this literature some youth may experience traumatic and damaging experiences in sex work, however, this is not definitively the case for all involved. At present the existing literature is comprised of health-based studies that are primarily quantitative and are not adequate in exploring the landscape of sex work experiences of youth. Furthermore, the experiences of males in youth sex work studies, and sex work studies more broadly, does not capture the nature of their lives and experiences from a social or cultural perspective (Smith et al., 2013). In many 
instances, gaps in this research area may exist because they have been previously addressed from rigid methodological approaches, therefore this article is as an example of the kind of data that can be extrapolated from stories, and serves to highlight that qualitative approaches can assist in uncovering different questions relating to sex work experiences that could be addressed in largescale quantitative studies.

Men engaged with sex work are often stigmatised (Minichiello \& Scott, 2014) and have drawn parallels with 'recruitment' into homosexuality which has been conflated with child sex abuse of youth (Crofts, 2014). Male youths in sex work are often seen as victims to the depravity of gay men and believed to be significantly in need of 'care' and 'protection' (Ditmore, 2011). Youth male sex work has typically occupied only marginal public space, often relying on known 'gay beats' or in adjoining urban spaces that were known as being 'gay' or 'gay friendly,' for example, 'the Wall' in Sydney's urban suburb of Darlinghurst (Crofts, 2014). Not only is youth male sex work hidden or clandestine in society with its relegation to 'gay spaces,' it also remains significantly hidden in academic literature, although there has been some interest in the domain of the social sciences. However, within the available literature little is shared on how youth male sex workers experience stigma and its effects on social and emotional wellbeing, let alone strategies to prevent the effects of such stigma in the Indigenous Australian context.

The geographic and population size of Indigenous Australian males in sex work is unknown although it is understood that Aboriginal sex workers are estimated to represent $20-23 \%$ of the sex industry (Donovan et al., 2012). Further, Aboriginal sex workers are usually thought to be involved in street-based economies (Donovan et al., 2012), as opposed to brothel or private work. This data is outdated and somewhat unreliable as the estimation is drawn from a New South Wales-based survey that is reflective of the greater Sydney region and does not include information from rural and remote areas, from those that do not identify as 'sex workers,' and is not inclusive of Indigenous Australian male and transgender sex workers. Furthermore, this data does not capture the uptake of technologies by Indigenous people, particularly youth (Carlson, 2020).

Although there have been several quantitative surveys on the sex worker population generally within Australia the research specifically on Indigenous sex workers remains limited, and further research is required. By centring on a single narrative, the scope of existing academic literature is expanded. The inclusion of a rich and in-depth account of an Indigenous cismale person's experience of selling sex is wielded to create new knowledge, challenge assumptions and contest dominant discourse shining light on how involvement in the sex industry encompasses a range of diverging meanings, motivations, and practices. Jack is a young, gay, cis-male, Indigenous Australian sex worker. These multiple identities are part of Jack, being Indigenous, young, gay, male, and a sex worker, they are all cultural, they intersect and shape belief systems, knowledges, meanings, interactions, and self-worth (O'Sullivan, 2019). In this article I will discuss how these cultural identities influence Jack's sense of social and emotional wellbeing in both positive and negative ways. This influence shapes and produces the way in which Jack feels that he is accepted and included in his social and cultural communities. The tensions between Jack's identities and his sense of acceptance and inclusion can offer ways of thinking through the difficulty of negotiating these spaces and the implications they have for social, cultural and political thought and action both within and outside of Indigenous communities. An application of Indigenous Standpoint Theory, and the concept of Indigenous social and emotional wellbeing, helps draw out meaning from Jack's narrative that highlights the different ways that sex work is lived.

\section{Positionality}

Before outlining the conceptual framework applied in this article, it is important that I introduce myself, and detail my lens of analysis used within this article. Framing my cultural connection and positionality to the project is an important and integral foundation of undertaking research with and for Indigenous peoples (O'Sullivan, Hill, Bernoth, \& Mlcek, 2016; Walter, 2013). I am a cisgender Indigenous Australian woman from the Wiradjuri nation in Central-Western New South Wales, I also identify as lesbian/queer. Situating myself in the research is demonstrative of my social/cultural/political positioning, and my Indigenous ontological (ways of being), epistemological (ways of knowing), axiological (accountabilities and values) and methodologies (ways of approach) frameworks in which I operate (Martin \& Mirraboopa, 2003). As an Indigenous person doing Indigenous research I have accountabilities and responsibilities to other Indigenous people, and to my own communities (for example, my Indigenous family, the Indigenous communities in which I live and work, my ancestral home, as well as the broader national Indigenous community). In conducting this research, I have drawn on my experiences as both an Indigenous queer person to view, analyse, and interpret the literature and narratives of participants in the study. This research comes from a position that is partial and situated by my Indigenous standpoint: According to Haraway (1991, p. 196), "[t]he only way to find a larger vision is to be somewhere in particular."

However, I do emphasise that although the participant in this article and I both identify as 'queer,' I do not suggest that we, or our experiences and knowledges are the same. I have taken this strength-based position to mobilise and liberate the collective sexual agency we possess as Indigenous Australian peoples and use my position to catapult our voices and knowledges. It is 
composed of shared meanings and social/cultural norms of Indigenous peoples, not as an effort to produce a grand narrative or provide a sense of pan-Aboriginality. Rather this positioning is a basis of shared meanings that make understanding aspects of Indigenous Australia visible. The privileging of Indigenous voice is intended to un-silence and demarginalise our position as queer Indigenous Australians and our voices are raised to bolster knowledges of our own sexual landscapes. My intention as an Indigenous Australian schol$a r$ is to assert Indigenous scholarly narratives of agency, autonomy, and self-determination. Therefore, I take an Indigenous Standpoint in the research methodology and the research methods employed within the study.

\section{Conceptual Framework}

There are two distinct lenses in which this article is contextualised: Indigenous Standpoint Theory and the concept of Indigenous social and emotional wellbeing. Research with Indigenous Australians requires a thoughtful and ethical approach that demands responsibility and accountability (Rigney, 1999). Therefore, this article draws on Indigenous Standpoint Theory as this framework values and centres Indigenous voices and perspectives, it is appropriate here to bring Indigenous experiences, ways of knowing and doing to the fore (Martin \& Mirraboopa, 2003). Indigenous Standpoint Theory recognises knowledge as acquired through interaction, engagement, and relationships (Foley, 2003, 2008; Kwaymullina, 2016; Moreton-Robinson, 2013; Nakata, 2007). Importantly, Indigenous Standpoint Theory does not represent individuals as a homogenous group: Rather, it is a position that recognised Indigenous people are the "primary and most authentic sources of our own cultures and experiences" (Kwaymullina, 2016, p. 446) and that our stories, "however expressed or embodied, hold power, spirit and agency" (Kwaymullina, Kwaymullina, \& Butterly, 2013, p. 5; Nakata, 2007).

Accordingly, Indigenous peoples needs and interests are prioritised as a means of empowerment and self-determination (Moreton-Robinson, 2013), doing so locates Indigenous ways of knowing, being and doing (Martin \& Mirraboopa, 2003) to produce agency and autonomy within the research process, analysis and outcome (Tur, Blanch, \& Wilson, 2010). Bringing Indigenous voice and centring it in this way responds to coloniocentric stereotypes of Indigenous people and supports the (re)construction of Indigenous representations on our own terms (Sullivan, 2020a). I employ the term coloniocentric to emphasise the "coloniality of power" (Grosfoguel, 2011, p. 3) that stems from social, political, and historical conditions that are influenced by whiteness, Western, Eurocentric, heteronormative, and Christian norms, which effect those that have been colonised, in this case Indigenous Australians. These 'norms' dominate hierarchies of power, social/cultural/political oppression, and unilateral knowledge that continues to be (re)produced within Western scholarship.

Untangling Indigenous people from pre-conceived stereotypes that limit us, is a key principle of Indigenous Standpoint Theory, as we strive to determine "who, what or how we can or can't be, to help see ourselves with some charge of the everyday, and to help understand our varied responses to the colonial world" (Nakata, 2007, p. 217). In this article I have looked to spaces where Indigenous representation is silenced or mis-understood with an emphasis on the position of young Indigenous male sex workers and their social and emotional wellbeing. Hopkins (2020), drawing on Sullivan (2020b), indicates that engaging in these spaces is crucial to the "construction and contestation of Indigenous Australian sexualities" (Hopkins, 2020, p. 6). The concept of social and emotional wellbeing is situated in a framework that places Indigenous Australian world views and culture as central. Connection to culture, family and community can shape Indigenous Australian experiences and is a key understanding of what social and emotional wellbeing means for Indigenous peoples (Gee, Dudgeon, Schultz, Hart, \& Kelly, 2014). Communities in the context of Indigenous Australia are largely recognised in multiple ways, and include physical, political, social, psychological, linguistic, economic, cultural, and spiritual spaces (Sullivan, 2020a), and are usually regarded as family or kinship groups, or localised communities of people who are geographically co-located (Carlson, 2016). Indigenous Australian conceptions of social and emotional wellbeing has developed and deepened understandings of mental health as being more than a singular entity (Raphael, 2000). Instead, it is a holistic view that encompasses the social, cultural, and emotional health and wellbeing as a whole of life view at both the level of the individual and of whole communities (Tsey, Harvey, Gibson, \& Pearson, 2009).

Critical to this study, and as a key analysis of Indigenous social and emotional wellbeing, is the concept of empowerment, whereby people gain power and can activate their agency and autonomy. As a theoretical construct, empowerment includes both the process and the outcomes that can transform and strengthen the way an individual thinks and feels about themselves and their place in the world (Tsey et al., 2009). Tsey et al. (2009) discuss individual empowerment as a vital component of social and emotional wellbeing in achieving whole of community structural change, and is understood as an "integrated process between the individual and the community" (Whiteside, 2009, p. 12). However, this places the onus on individuals to generate positive social/cultural/political structural change of the whole community of which they may have no control. This becomes a point of contention, if an individual is not accepted in their communities, how are they to expected to generate the structural changes required to be accepted, to facilitate the concept of Indigenous social and emotional wellbeing of whole communities? 
Empowerment is a connecting concept across Indigenous Standpoint Theory and Indigenous social and emotional wellbeing, which is underpinned by concepts of agency and autonomy, hence the relevance of application to this study. A useful principle to apply Indigenous Standpoint Theory is the recognition and amplification of Indigenous agency as framed within the limits and possibilities of what can be known (Nakata, 2007). Indigenous Standpoint Theory and Indigenous concepts of Social and Emotional Wellbeing can invigorate and strengthen Indigenous peoples and support efforts to achieve self-determination. In an academic context, these two theoretical orientations assist us to read narratives such a Jack's in a way that fosters self-determination and recognition of agency, as opposed to sometimes tired readings of victimisation and marginalisation. Therefore, the analysis of Jack's narrative, and the re-telling of his story in this article, is an act of agency and resistance, and is positioned in this article as more than representation; rather, it re-tells Jack's story to create places, space, peoples and knowledges (Behrendt, 2019). The bringing together of Indigenous Standpoint Theory and Social and Emotional Wellbeing is a useful framework in which to understand, interpret and analyse the histories and geographies of Jack.

\section{Methodology}

This article forms part of a doctoral study that explores the lives and experiences of seven cis-male, cis-female and transgender Aboriginal sex workers, some of whom also identify as sexually diverse. All participants in the study identify as Indigenous Australian or Aboriginal and all use these terms interchangeably; it is also important to note that I identify as Indigenous Australian. Each participant was over 18 years old at the time of data collection. This study has ethical approval through an Australian university ethics committee process, and all participants involved took part with informed ethical consent which could be withdrawn at any time. Each research participant either self-selected or were assigned a pseudonym to maintain their anonymity and these strategies help to give opportunities for assertion of agency and necessary protection of identity. Further each participant was compensated for their time, as appropriate according to ethical guidelines and best practice for both Indigenous peoples, and sex workers (AIATSIS, 2012; Jeffreys, 2010).

Although the larger study included people of diverse gender and sexual identities, the data presented here were collected through a single qualitative semistructured interview with a cis-male. The interview consisted of a set of questions related to his experiences as a sex worker and was subsequently analysed using Indigenous Standpoint Theory. Current academic literature does not account broadly for Indigenous Australian sex workers, particularly so those that fall into categories of being youth, queer, and Indigenous. Therefore, the inclusion of a single narrative is warranted as this story provides a unique working knowledge of the sex industry as an Indigenous gay male, providing a rich and detailed contribution to the literature.

\section{Getting to Know Jack}

Jack, an Aboriginal man, identifies as young, gay, male. Jack also works as a sex worker. "I don't really like all the labels," he said, "I am not all these things all the time. Sometimes, who, or what I am depends on who I am with." He was born and raised in a country town of New South Wales and moved to the city at the age of 16 years old. He says, "I left my family and community and moved [to the city] to get away from them. They didn't like that I was gay. I was the only gay kid in the community-that they knew about." Here Jack expresses that he did not feel able to stay at home due to homophobia within the family and in his broader community. Jack details:

Growing up there were lots of comments being made about gay people, and things that were considered to be gay...like wearing certain clothes, or even what you drank. My mum used to say things like only white women and gay men drink wine. Really stupid stuff, but it stuck. I really tried to hide who I was...but some people just, like, it's like they knew. I would hear slurs like, faggot and fairy. It really stressed me out. I couldn't be who I wanted... when I was sixteen, nearly seventeen, I left home. I moved to Sydney in with some friends who I knew there. It was a great time.

The significance of sexual diversity in Indigenous communities has been minimized and obscured by the force of social and cultural taboos (Farrell, 2016; Sullivan \& Day, 2019a), and is rarely reflected in the literature. The distancing from sexual diversity in some Indigenous communities, I would argue, stems directly from the impact of the invasion and subsequent colonisation of the country now known as Australia. Colonisation brought with it Western and Christian values and beliefs about sexuality and gender (Sullivan, 2018a). The coloniocentric narrative has infiltrated some Indigenous communities and individuals to the point where Christian values are now conflated with Indigenous Australian cultural ways (Jolivette, 2018). An example of this conflation can be found in a 2013 social media post by infamous Indigenous Australian boxer Anthony Mundine who wrote homophobic remarks in response to a gay Indigenous male couple who were featured in the television series Redfern Now. He wrote (as cited in "Anthony Mundine says homosexuality and Indigenous culture don't mix," 2013, para 5):

Watching redfern now \& they promoting homosexuality! (Like it's ok in our culture) that ain't in our culture \& our ancestors would have there [sic] head for 
it! Like my dad told me GOD made ADAM \& EVE not Adam \& Steve.

Such belief systems demonstrate the importance of acknowledging and affirming sexual diversity across Indigenous communities as this discrimination and homophobia can have a direct impact on social and emotional wellbeing. As a gay Indigenous male, Jack did not feel that he could remain part of his family and community and be an 'out' gay man: "I was not kicked out of home, I chose to leave, it did make me sad, but I was also really happy to be free of the bullshit." To express his identity safely, Jack made his way to the city, living with friends and to support himself financially, he eventually turned to sex work. He says:

I never intended to go into sex work. It was a bit of an accident to start with. I was having sex and enjoying the Sydney queer scene...here I am accepted for who I am.... I would often find that, probably because of my age, I was given lots of gifts. I guess I was a bit of a sugar baby. I got clothes, shoes, cigarettes, and alcohol. Nights in swanky hotels, one guy even took me with him on holidays. Sometimes I was given cash. Everything I got was expensive. I liked it. Eventually I decided to actually make it my job.... probably really started actual 'sex work' when I was 18 , or 19 . I wanted to go to Uni[versity] so I needed something stable, but didn't take up my time. I only do high-end work... when I first started I worked for an [escort] agency, now though I see regulars [clients] only.

Here Jack discusses his experience of becoming a sex worker. Jack's experiences are not usually recorded in academic literature, the voices of young, gay Indigenous males who are also sex workers are rarely, if ever, featured. His experience provides an example that refutes academic discourses of males engaged in sex work as being trafficked, homeless, exploited, in poverty, or in need of protection (Ditmore, 2011). The indication to Jack being a 'sugar baby' could imply sexual exchanges that could be read as coercive, or evidence of deviancy on the part of older men (Crofts, 2014). A sugar baby refers to someone who participates in dating, talking, or having sexual interactions with a sugar daddy or sugar mummy. The arrangement replicates a dating relationship, instead of exchanging money for a single service, a sugar baby may receive material goods and benefits, such as money or accommodation, in exchange for being in the relationship, typically with someone who is older (Rakić, 2020). Indeed, Jack's account of his role as a sugar baby, is not a coercive, or deviant act. Conversely, he sees his role as a sugar baby as a powerful and niche act of agency that enabled him to access money and material goods, sexual experiences, and social status. Agency in this context highlights Jack's ability to make autonomous decisions in the pursuit of his desires. Agency is struc- tured by a person's socially and culturally shaped position and can be constrained in application by their social, cultural, political, and economic circumstances (Nakata, 2007). Jack's statement clearly elucidates that he has made an agentic choice, one that works for him and his schedule, and capitalises his social status and physical desirability, he adds:

I am hot, young, buff and hung....I'm also clean, I am not a junkie, I am fit and healthy. I am really masc[uline], I work hard to play that role. I can command how much I want to make. I don't fuck for less than a thousand bucks.

Sex workers capitalise on their bodies to work and promote themselves as appealing, sexual, and viable (Browne \& Minichiello, 1996). Notwithstanding the transgressions of social and cultural taboos, capitalising on the body is often seen by sex workers as "another day in the office" (Perkins \& Lovejoy, 2007, p. 153) and similarly, sex work for Jack is a way to earn an income through his body and sexuality. Nussbaum (1998, p. 693) argued that we all "take money from the use of our body" (p. 693), then the consideration of sex work as somehow unique in terms of bodily exploitation could be read as inconsistent and hypocritical. Except for the unemployed and the independently wealthy, she contends that making money from the body is not different from other forms of work. This sentiment is implied in Jack's statement: "You wouldn't hold it against a carpenter for using their hands to make money, why is it so different that I use my body?" Evidently, he does not feel that he is need of 'care' and 'protection' (Ditmore, 2011), or that he is being exploited or that he is doing sex work through lack of choice. He claims:

I'm a good lookin' guy. I know what I have and I know what others want. This is my time to make as much money as I can. I'm not gonna be pretty forever you know...later when I'm old I will go back to office work. I've been doing some consultancy work to keep my 'normal' career going for later, but for now I just want to make a tonne of cash and have fun.

Jack identifies as a 'high-end' worker, and that sex work, and being part of the queer scene has had positive impact on his sense of self-worth, being in a position to command such income for his attractiveness to other gay males is meaningful to Jack: "I am accepted for who I am, and what I do," he says. For Jack, his youth is an important part of his identity, as both a gay male, and as a sex worker. He is emboldened by his masculinity, his looks, and his youth. Being young is an exciting time for Jack, he is able to explore different aspects of his identity and has been able to engage freely as a gay man. The importance of being recognised and accepted for being queer is evident. For Jack sex work is a financially viable option that allows him to live in the city and be close to the gay 
scene is a positive experience, thus contributing to positive social and emotional outcomes for him.

However, although Jack is now accepted for being gay, he does not feel that he is accepted for being Indigenous:

I definitely don't advertise or discuss that I am Indigenous with my clients. You have to promote yourself in certain ways. Being Aboriginal is not considered a sexy thing in the gay community. There's lots of racism, you know, and all sorts of other prejudices, like being Asian, or fat....I guess I play into that when I am working. I am too dark to say I am white...other guys cannot make as much money as me, maybe they are too skinny, or too old, too fat, too something. It's interesting, you know, I am brown, so I can get away with being tan, but not black.

Here Jack identifies that although his sexuality is accepted, his culture is not. He declares his unwillingness to advertise as being Indigenous Australian and does not discuss his Aboriginality with his clients due to inherent racism in the queer scene. Jack is therefore carefully curating and managing his identities to fulfil his image as sexually attractive to other gay men but must also negotiate inherent racism. The curation of online identities by Indigenous people (Carlson, 2020) and other people of colour (Logan, 2017) online suggests that sexual 'preference' is highly racialised. As Jack points out, being Indigenous is not financially viable as it is not considered to be 'sexy.' Carlson (2020, p. 135) has noted in her research with Indigenous people and dating apps, that the racism that prevails against Indigenous people is not always related to physical or "phenotypical factors" that influence attractiveness or desirability, rather it is rooted in social and political overtures of "conventional racism." Further, Jacks' narrative is indicative of the social exclusion that can be felt by Indigenous queer people from their social and cultural communities (Sullivan \& Day, 2019b). In his Indigenous community Jack is socially and culturally excluded, in the queer community Jack is culturally excluded. Jack is dependent on his communities for acceptance and affirmation. Indigenous Standpoint Theory helps us to see that this is a difficult and tenuous social/cultural/political positioning that occurs at the cultural interface (Nakata, 2007). Jack experiences marginalisation that is contingent on the cultural space that he is inhabiting, the application of Indigenous Standpoint Theory shines light on the racial oppression and coloniocentric processes that (re)produce, inscribe and maintain difference between Indigenous and 'other' bodies (Radcliffe, 2018). For Jack, the only place that he feels that he gets complete sense of self-value is from other Indigenous sex workers. He says:

Over the years I have met heaps of Indigenous queers who have moved to the city because of the homophobic shit in their communities. Many of them have done sex work here and there. When we start yarnin' and feelin' comfortable with each other you start to hear stories. Sex work is pretty common, you know, I don't know...but I know a few guys, and girls, that have worked the streets over the years. I like hanging out with them, sometimes it feels like it's the only time I can just be myself. I don't have to lie about what I do, or who I am. I can just be.

Yarning is an Indigenous Australian cultural term that, at its simplest explanation, is a synonym of conversation. It is a process of storying and storytelling that can be both formal and informal depending on its use (Barlo, Boyd, Pelizzon, \& Wilson, 2020). The context in which Jack employs the term is suggests a conversation that involves the sharing of stories. For Jack, it is yarning and feeling with his peers, that are also Indigenous sex workers, that he finds a sense of belonging. Few studies of Indigenous sex workers explore belonging and the locality of belonging spaces as mediators of social exclusion and inclusion (Sullivan, 2018b). Building this sense of belonging is a source of empowerment for Jack. Knowing people like him, give him a sense of belonging and community, highlighting that a sense of empowerment "enhances individual social and emotional wellbeing" (Tsey et al., 2009, p. 9). At present, the literature discusses the concept of Indigenous social and emotional wellbeing and expresses the importance of whole of community wellbeing as integral to the individual. The limits in the literature express 'whole of community' as being connected to land and country or geographically located, and familial relationships. For queer Indigenous people, and other apparent 'deviants,' such as sex workers, this is not always possible (Sullivan, 2020a). However, it is clear from Jack's story that building and maintaining connection to Indigenous community can be understood in multiple ways. His connection to other queer, and sex worker, Indigenous peoples has given him a space in which to connect to his culture by forming his own communities of practices, values, and knowledges (Farrell, 2016).

\section{Discussion}

For Jack, sex work is a space of financial stability and is also where he has been able to explore his sexual expression and self-value. However, despite being socially and financially well, his feelings of social and emotional wellbeing are limited by the lack of social/cultural validation and belonging, resulting in social exclusion. For Indigenous people, a sense of belonging is an important aspect of identity and wellbeing (Franklin, 2014). The concept of social exclusion denotes multifarious interactions, that include cultural marginalisation, restricted spatial mobility, and social inequalities (Moore, 2014). Indigenous social standing is a critical factor underpinning social inequality (Sullivan, 2018a), challenging this social position is important toward achieving social justice and so we need to be explicit- 
Iy political in advocating for it within our communities (Hopkins, 2020).

Retuning to Tsey et al. (2009), who discussed the importance of individual empowerment as essential to community structural change, it is my position that Jack has achieved that, just not in the way that is understood currently in the literature. Indigenous spaces are emerging for Indigenous queer people that should be thought of, and understood, as Indigenous communities. For example, Jack's community with other likeminded people, although an informal and fluid group, they are a community that have built connection and a sense of belonging to enhance their own sense of social and emotional wellbeing as empowered people. Additionally, there are community-based groups that are working toward social/cultural/political structural change for Indigenous queer people such as, 'Black Rainbow,' and 'Blaq Aboriginal Corporation.' Both are Indigenous community advocate groups who provide spaces of social inclusion to Indigenous queer people and are crucially working toward building capacity within familial and geographically located Indigenous communities. This work is vital, it recognises Indigenous queer people as always existing within our familial and kinship communities, it is my position that our inclusion within these communities is fundamental to the social and emotional wellbeing of those communities-they need us.

The concept of whole of community in Indigenous social and emotional wellbeing is a narrowed vision and understanding of what constitutes 'Indigenous community.' The concept of 'whole of community' needs to be interrogated further and recognised as plural. Additionally, the concept of empowerment is elemental and can occur on multiple levels, including at the individual and community level, however, should not imply that you cannot have one without the other. Furthermore, this article has bought to the fore the importance of capacity building within and outside of Indigenous communities. I highlight that experiences of belonging and connection are contextual, being closely linked to different forms of social and cultural networks, and the negative and positive implications for social and emotional wellbeing.

\section{Conclusion}

The experiences of sex workers are often more nuanced than debates have led us to believe, particularly when such arguments fail to offer Indigenous Australian sex workers' perspectives. Sex based research with Indigenous people poses challenges. For many, it implies a focus on negative issues and exacerbates anxieties around particular social and cultural taboos. As a result, there has been an apparent reluctance in the research community to undertake sex and sexuality research directly involving Indigenous people. However, Indigenous involvement in sex based research can challenge the social and cultural signification of sexuality and gender and, it can also shine light on how queer and sex worker are identifiers that are positioned outside the cultural (hetero)norms of sex-gender and inclusion/exclusion dualities that exist in some Indigenous and non-Indigenous communities.

This article has explored sex work through the lenses of Indigenous Standpoint Theory and social and emotional wellbeing drawing attention to the intersections of culture and sexuality with the consequences of Jacks' social and emotional wellbeing discussed. Jacks' story highlights the way in which Indigenous people, and non-Indigenous people disregard Indigenous gender and sexual diversity leading to social exclusion that can have a detrimental effect on social and emotional wellbeing. Providing a story told by an Indigenous youth is evidence that Indigenous communities are still subjected to coloniocentric ideologies that stifle our identities and philosophies. As queer and Indigenous people, we must assert our multiply located and queer identities and speak back against coloniocentric narratives that seek to homogenise our communities, and Indigenous people more broadly. More work is needed to better understand the practice of sex work for queer Indigenous youth and its impacts on social/cultural relations, sexuality and gender, and social and emotional wellbeing.

\section{Acknowledgments}

I wish to thank Jack for the generosity in sharing his story. I also acknowledge and thank my supervisors A/Prof Sandie Suchet-Pearson and Dr Jessica McLean, for all their guidance and patience.

\section{Conflict of Interests}

The author declares no conflict of interests.

\section{References}

Anthony Mundine says homosexuality and Indigenous culture don't mix after watching Redfern Now. (2013, 1 November). ABC News. Retrieved from https://www.abc.net.au/news/2013-11-01/ anthony-mundine-aborigines-homosexual-gay/ 5063836?nw $=0$

AIATSIS. (2012). Guidelines for ethical research in Australian Indigenous studies. Canberra: Australian Institute of Aboriginal and Torres Strait Islander Studies.

Barlo, S., Boyd, W. E., Pelizzon, A., \& Wilson, S. (2020). Yarning as protected space: Principles and protocols. AlterNative: An International Journal of Indigenous Peoples, 16(2), 90-98.

Behrendt, L. (2019). Indigenous storytelling: Decolonizing institutions and assertive self-determination. Implications for legal practice. In J.-A. Archibald Q'um Q'um Xiiem, J. B. Jun Lee Morgan, \& J. De Santolo (Eds.), Decolonizing research: Indigenous storywork as methodology (pp. 175-186). London: Zed Books. 
Browne, J., \& Minichiello, V. (1996). The social and work context of commercial sex between men: A research note. The Australian and New Zealand Journal of Sociology, 32(1), 86-92.

Carlson, B. (2016). The politics of identity: Who counts as aboriginal today? Canberra: Aboriginal Studies Press.

Carlson, B. (2020). Love and hate at the cultural interface: Indigenous Australians and dating apps. Journal of Sociology, 56(2), 133-150.

Crofts, T. (2014). Regulation of the male sex industry. In V. Minichiello \& J. Scott (Eds.), Male sex work and society (pp. 178-197). New York, NY: Harrington Park.

Ditmore, M. H. (2011). Prostitution and sex work. Santa Barbara, CA: ABC-CLIO.

Donovan, B., Harcourt, C., Egger, S., Watchirs Smith, L., Schneider, K., Kaldor, J. M., .. . Tabrizi, S. (2012). The sex industry in New South Wales: A report to the NSW Ministry of Health. Sydney: Kirby Institute, University of New South Wales.

Farrell, A. (2016). Lipstick clapsticks: A yarn and a Kiki with an Aboriginal drag queen. AlterNative: An International Journal of Indigenous Peoples, 12(5), 574-585.

Foley, D. (2003). Indigenous epistemology and Indigenous standpoint theory. Social Alternatives, 22(1), 44-52.

Foley, D. (2008). An Indigenous standpoint theory. In A. Gunstone (Ed.), History, politics and knowledge: essays in Australian Indigenous knowledge (pp. 113-133). Vitoria: Australian Scholarly Publishing.

Franklin, C. (2014). Belonging to bad: Ambiguity, Parramatta girls and the Parramatta Girls Home. Geographical Research, 52(2), 157-167.

Frederick, T. (2014). Diversity at the margins: The interconnections between homelessness, sex work, mental health, and substance use in the lives of sexual minority homeless young people. In V. R. Panfil \& D. Peterson (Eds.), Handbook of LGBT communities, crime, and justice (pp. 473-501). Berlin: Springer.

Gamson, J., \& Moon, D. (2004). The sociology of sexualities: Queer and beyond. Annual Review of Sociology, 30, 47-64.

Gee, G., Dudgeon, P., Schultz, C., Hart, A., \& Kelly, K. (2014). Aboriginal and Torres Strait Islander social and emotional wellbeing. Working Together: Aboriginal and Torres Strait Islander Mental Health and Wellbeing Principles and Practice, 2, 55-68.

Grosfoguel, R. (2011). Decolonizing post-colonial studies and paradigms of political-economy: Transmodernity, decolonial thinking, and global coloniality. Transmodernity: Journal of Peripheral Cultural Production of the Luso-Hispanic World, 1(1), 1-38.

Haraway, D. J. (1991). Simians, cyborgs and women: The reinvention of nature. London: Free Association Books.

Hopkins, P. (2020). Social geography III: Committing to social justice. Progress in Human Geography. Advance online publication. https://doi.org/

\section{$10.1177 / 0309132520913612$}

Hubbard, P. (2019). Sex and the city: Geographies of prostitution in the urban West. Oxon: Routledge.

Jeffreys, E. (2010). Sex worker-driven research: Best practice ethics. Dialogue, 8(1), 1-20.

Jolivette, A. (2018). Examining internal traumatic gay men's syndrome (ITGMS) and queer indigenous citizenship. Social Alternatives, 37(4), 44.

Kwaymullina, A. (2016). Research, ethics and Indigenous peoples: An Australian Indigenous perspective on three threshold considerations for respectful engagement. AlterNative: An International Journal of Indigenous Peoples, 12(4), 437-449.

Kwaymullina, A., Kwaymullina, B., \& Butterly, L. (2013). Living texts: A perspective on published sources, Indigenous research methodologies and Indigenous worldviews. International Journal of Critical Indigenous Studies, 6(1), 1-13.

Lantz, S. (2005). Students working in the Melbourne sex industry: Education, human capital and the changing patterns of the youth labour market. Journal of Youth Studies, 8(4), 385-401.

Logan, T. D. (2017). Economics, sexuality, and male sex work. Cambridge: Cambridge University Press.

Martin, K., \& Mirraboopa, B. (2003). Ways of knowing, being and doing: A theoretical framework and methods for indigenous and indigenist re-search. Journal of Australian Studies, 27(76), 203-214.

Mehlman-Orozco, K. (2015). Safe Harbor legislation for juvenile victims of sex trafficking: A myopic view of improvements in practice. Social Inclusion, 3(1), 52-62.

Mendes, P., Snow, P., \& Baidawi, S. (2014). The views of service providers on the challenges facing young people also involved in the youth justice system transitioning from out-of-home care. Journal of Policy Practice, 13(4), 239-257.

Minichiello, V., \& Scott, J. (2014). Male sex work and society. New York, NY: Columbia University Press.

Moore, T. (2014). Aboriginal agency and marginalisation in Australian Society. Social Inclusion, 2(3), 124-135.

Moreton-Robinson, A. (2013). Towards an Australian Indigenous Women's Standpoint Theory: A methodological tool. Australian Feminist Studies, 28(78), 331-347.

Nakata, M. (2007). An Indigenous Standpoint Theory. In M. Nakata (Ed.), Disciplining the savages savaging the disciplines (pp. 213-217). Sydney: Aboriginal Studies Press.

Nussbaum, M. C. (1998). "Whether from reason or prejudice": Taking money for bodily services. The Journal of Legal Studies, 27(Suppl. 2), 693-723.

O'Sullivan, S. (2019). A lived experience of Aboriginal knowledges and perspectives: How cultural wisdom saved my life. In J. Higgs (Ed.), Practice wisdom: Values and interpretations (pp. 107-112). Leiden: Brill Sense.

O’Sullivan, S., Hill, B., Bernoth, M., \& Mlcek, S. (2016). 
Indigenous approaches to research. In Z. Schneider, D. Whitehead, G. LoBiondo-Wood, \& J. Haber (Eds.), Nursing and midwifery research: Methods and appraisal for evidence-based practice $5 e$ (pp. 257-276). Sydney: Elsevier.

Perkins, R., \& Lovejoy, F. (2007). Call girls: Private sex workers in Australia. Crawley: University of Western Australia Press.

Radcliffe, S. A. (2018). Geography and indigeneity II: Critical geographies of indigenous bodily politics. Progress in Human Geography, 42(3), 436-445.

Rakić, V. (2020). Prostitutes, sex surrogates and sugar babies. Sexuality \& Culture, 24. https://doi.org/ 10.1007/s12119-020-09702-y

Raphael, B. (2000). Promoting the mental health and wellbeing of children and young people. Canberra: Commonwealth Department of Health and Aged Care.

Rigney, L.-I. (1999). Internationalization of an Indigenous anticolonial cultural critique of research methodologies: A guide to Indigenist research methodology and its principles. Wicazo sa Review, 14(2), 109-121.

Sanders, T. (2013). Sex work. London: Routledge.

Smith, M. D., Grov, C., Seal, D. W., \& McCall, P. (2013). A social-cognitive analysis of how young men become involved in male escorting. Journal of Sex Research, 50(1), 1-10.

Sullivan, C. T. (2018a). Indigenous Australian women's colonial sexual intimacies: Positioning indigenous women's agency. Culture, Health \& Sexuality, 20(4), 397-410.

Sullivan, C. T. (2018b). Majesty in the city: Experiences of an Aboriginal transgender sex worker in Sydney, Australia. Gender, Place \& Culture, 25(12), 1681-1702.

Sullivan, C. T. (2020a). Who holds the key? Negotiating gatekeepers, community politics, and the "right" to research in Indigenous spaces. Geograph- ical Research, 58(4). https://doi.org/10.1111/17455871.12415

Sullivan, C. (2020b). Indigenous Australian sexualities explored through the lens of sex work. In A. Datta, P. Hopkins, L. Johnston, E. Olson, \& J. M. Silva (Eds.), Routledge handbook of gender and feminist geographies (pp. 17-26). London: Routledge.

Sullivan, C. T., \& Day, M. (2019a). Indigenous transmasculine Australians \& sex work. Emotion, Space and Society, 32, 1-7. https://doi.org/10.1016/j.emospa.2019. 100591

Sullivan, C., \& Day, M. (2019b). Queer(y)ing Indigenous Australian higher education student spaces. The Australian Journal of Indigenous Education. https://doi. org/10.1017/jie.2019.19

Tsey, K., Harvey, D., Gibson, T., \& Pearson, L. (2009). The role of empowerment in setting a foundation for social and emotional wellbeing. Australian e-Journal for the Advancement of Mental Health, 8(1), 6-15.

Tur, S. U., Blanch, F. R., \& Wilson, C. (2010). Developing a collaborative approach to Standpoint in Indigenous Australian research. The Australian Journal of Indigenous Education, 39, 58-67.

van der Meulen, E., Durisin, E. M., \& Love, V. (2013). Selling sex: Experience, advocacy, and research on sex work in Canada. Vancouver: UBC Press.

Walter, M. (2013). The nature of social science research. In M. Walter (Ed.), Social research methods (3rd ed., pp. 3-22). Melbourne: Oxford University Press.

Weitzer, R. (2009). Sociology of sex work. Annual Review of Sociology, 35, 213-234. https://doi.org/10.1146/ annurev-soc-070308-120025

Whiteside, M. (2009). A grounded theory of empowerment in the context of Indigenous Australia (Unpublished Doctoral dissertation). James Cook University, Australia.

\section{About the Author}

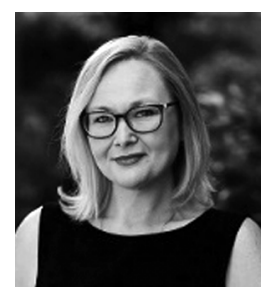

Corrinne Sullivan is an Aboriginal scholar from the Wiradjuri Nation in Central-West New South Wales. She is a Senior Lecturer in Geography at Western Sydney University, Sydney, Australia, and a PhD candidate at Macquarie University, Sydney, Australia. Her research interests are multi-disciplinary and focus broadly on experiences and effects of body and Identity in relation to Aboriginal and Torres Strait Islander peoples. Corrinne's knowledges stem from the disciplines of Indigenous Studies and Human Geography, she utilises both to understand the ways in which Aboriginal and Torres Strait Islander peoples are affected by their experiences of space and place. 